\title{
Analysing visual pattern of skin temperature during submaximal and maximal exercises
}

\author{
Gorkem Aybars Balci ${ }^{\mathrm{a}, *}$, Tahsin Basaran ${ }^{\mathrm{b}}$, Muzaffer Colakoglu ${ }^{\mathrm{a}}$ \\ ${ }^{a}$ Ege University, School of Physical Education and Sports, Izmir, Turkiye \\ b Izmir Institute of Technology, Department of Architecture, Izmir, Turkiye
}

\section{H I G H L I G H T S}

-We examined skin temperature changes in similar body surface area cohort.

- A structural relation was observed in skin temperature variations among participants.

- Temperature pattern of skin was different between maximal and submaximal exercise.

- Thermal kinetic analysing may be useful tool for monitoring thermoregulations.

- New method was examined for determining skin temperature by infrared thermography.

\section{A R T I C L E I N F O}

\section{Article history:}

Received 11 April 2015

Available online 29 December 2015

\section{Keywords:}

Exercise intensity

Infrared thermography

Thermal kinetics

Thermoregulation

\begin{abstract}
A B S T R A C T
Aims of this study were to examine our hypotheses assuming that (a) skin temperature patterns would differ between submaximal exercise (SE) and graded maximal exercise test (GXT) and (b) thermal kinetics of $T_{\text {skin }}$ occurring in SE and GXT might be similar in a homogenous cohort. Core temperature $\left(T_{\text {core }}\right)$ also observed in order to evaluate thermoregulatory responses to SE and GXT. Eleven moderately to well-trained male athletes were volunteered for the study (age: $22.2 \pm 3.7$ years; body mass: $73.8 \pm 6.9 \mathrm{~kg}$; height: $181 \pm 6.3 \mathrm{~cm}$; body surface area $1.93 \pm 0.1 \mathrm{~m}^{2}$; body fat: $12.6 \% \pm 4.2 \%$; $\dot{V} \mathrm{O}_{2 \max }$ : $54 \pm 9.9 \mathrm{~mL} \mathrm{~min}^{-1} \mathrm{~kg}^{-1}$ ). Under stabilized environmental conditions in climatic chamber, GXT to volitional exhaustion and 20 -min $\mathrm{SE}$ at $60 \%$ of $\mathrm{VO}_{2 \max }$ were performed on cycle ergometer. Thermal analyses were conducted in 2-min intervals throughout exercise tests. $T_{\text {skin }}$ was monitored by a thermal camera, while $T_{\text {core }}$ was recorded via an ingestible telemetric temperature sensor. Thermal kinetic analyses showed that $T_{\text {skin }}$ gradually decreased till the $7.58 \pm 1.03$ th minutes, and then initiated to increase till the end of SE (Rsqr $=0.97)$, while $T_{\text {skin }}$ gradually decreased throughout the GXT $(\mathrm{Rsqr}=0.89)$. Decrease in the level of $T_{\text {skin }}$ during the GXT was significantly below from the SE $[\mathrm{F}(4,40)=2.67, p=0.07$, $\left.\eta_{p}{ }^{2}=0.211\right]$. In the meantime, $T_{\text {core }}$ continuously increased throughout the SE and GXT $(p<0.05)$. Both GXT and SE were terminated at very close final $T_{\text {core }}$ values $\left(37.8 \pm 0.3{ }^{\circ} \mathrm{C}\right.$ and $38.0 \pm 0.3^{\circ} \mathrm{C}$, respectively; $p>0.05$ ). However, total heat energies were calculated as $261.5 \mathrm{~kJ} / \mathrm{m}^{2}$ and $416 \mathrm{~kJ} / \mathrm{m}^{2}$ for GXT and SE, respectively $(p<0.05)$. Thus, it seems that SE may be more advantageous than GXT in thermoregulation. In conclusion, $T_{\text {core }}$ gradually increased throughout maximal and submaximal exercises as expected. $T_{\text {skin }}$ curves patterns found to be associated amongst participants at both GXT and SE. Therefore, $T_{\text {skin }}$ kinetics may ensure an important data for monitoring thermoregulation in exercise.
\end{abstract}

() 2015 Elsevier B.V. All rights reserved.

\section{Introduction}

Chemical energy is converted to mechanical energy approximately $20 \%$ depending on type of exercise and athletic status. Remaining part is released into the environment as heat. Thus,

\footnotetext{
* Corresponding author.

E-mail addresses: gorkem.aybars.balci@ege.edu.tr (G.A. Balci), tahsinbasaran@ iyte.edu.tr (T. Basaran), muzaffer.colakoglu@ege.edu.tr (M. Colakoglu).
}

human body is not very efficient [1]. Air temperature, radiant temperature, relative humidity and air flow velocity are four main factors affecting the heat transfer mechanism of the human body [2]. Brain is a thermoregulatory centre of human body. Core temperature $\left(T_{\text {core }}\right)$ can be smoothly raised in the range of $36-39{ }^{\circ} \mathrm{C}$ with motor activities and chemical reactions. $T_{\text {core }}$ value greater than $39{ }^{\circ} \mathrm{C}$ is critical for human body [3,4]. For this reason, maintenance of $T_{\text {core }}$ in optimal range is crucial for human thermal comfort. During exercise, the blood flow is directed to active skeletal 
muscles and myocard in order to supply their metabolic needs. When heat stress increases, warmed blood is passed to the skin for exchanging the heat thus causing an increment in skin temperature.[5]. During a prolonged exercise, heat loss is limited in an attempt to maintain venous return and cardiac output [6]. Therefore, it can be interpreted that the skin blood flow has a dominant role in thermoregulation, and thus athletic performance [5].

Contact thermistors have been widely used to evaluate $T_{\text {skin }}$ by using different body parts [7]. However, these contact thermistors cause technical complications by preventing the heat loss from the skin. Moreover, the thermistors can analyse only a limited part of the surface on the body. In addition to using thermistors, thermal imaging is more advantageous for analysing skin temperature owing to its ability to analyse larger areas without contacting the skin $[8,9]$. In limited literature, the infrared thermography have been used to analyse $T_{\text {skin }}$ by multiple plot analysis, averaging around hottest pixels area, averaging total body segment temperatures and averaging geometric areas with or without markers [10-17].

Jay et al. emphasized that $T_{\text {core }}$ and sweating rate is not affected by fitness level while the same workload is used with participants having similar body surface area (BSA) [18]. If so, the total amount of heat exchange would be similar with the participants who have the same BSA.

The aim of this study was therefore to examine the changes in $T_{\text {skin }}$ during graded maximal exercise test (GXT) and submaximal cycling exercise (SE) at $60 \%$ of maximal oxygen consumption level $\left(\mathrm{VO}_{2 \max }\right)$ in a homogeneous BSA cohort by using a thermal camera. It was hypothesized that (a) $T_{\text {skin }}$ pattern in response to GXT differs from those of SE and (b) thermal kinetics of $T_{\text {skin }}$ occurring in both SE and GXT are similar amongst participants with similar BSA.

\section{Materials and methods}

\subsection{Participants}

The study was designed according to the rules and the principals of the Helsinki Declaration protocol and was approved by the university ethics committee (EGE.ETK.2009.09-3/18). Written informed consent was obtained after explanation of the nature of the study and risks involved in participating in the experiment. 11 moderately to well-trained male cyclists, track and field athletes and soccer players volunteered to take part in the study (age: $22.2 \pm 3.7$ years; body mass: $73.8 \pm 6.9 \mathrm{~kg}$; height: $181 \pm 6.3 \mathrm{~cm}$; BSA: $1.93 \pm 0.1 \mathrm{~m}^{2}$; body fat: $12.6 \% \pm 4.2 \%$; $\dot{V} \mathrm{O}_{2 \max }$ : $54 \pm 9.9 \mathrm{~mL} \mathrm{~min}^{-1} \mathrm{~kg}^{-1}$ ). The participants were involved in $5.8 \pm 2.3$ training sessions per week. Their mean athletic experience was $9.9 \pm 2.8$ years. Study protocol was completed within the period of six-days after the end of the competition season to minimize training effects. The volunteers consumed approximately $300 \mathrm{~mL}$ of natural water $1 \mathrm{~h}$ before their experiments. In addition, the testing time of day was replicated to minimize any effect of circadian variance for each volunteer. Participants were requested not to take part in any exhaustive exercise during the course of the study. None of the participants suffered from any injuries or were under any specific medication. Volunteers were also asked not to exercise for 24-h prior to the experimentation. Since their anatomical differences may limit surface area subjected to thermography, female athletes did not take part in the study.

\subsection{Experimental design}

A cross-sectional study design was used for this controlled laboratory experiment. Before performance test, subjects visited laboratory to have their body mass and height measurements. Then, a familiarization session was conducted to adapt volunteers to experimental study. A series of pilot studies were conducted before main experiments. The purpose of the pilot studies was to find out $T_{\text {skin }}$ variances of different body surfaces, to ensure which body regions were accurate to measure $T_{\text {skin. }}$. After pilot studies, a submaximal graded exercise test was applied to evaluate workloads corresponding to their individual ventilatory threshold. After a 45-min rest, a GXT was performed to reveal their $\mathrm{VO}_{2 \max }$. A subsequent day, constant-load SE was conducted at \%60 of $\mathrm{VO}_{2 \max }$ level. During the GXT and SE, thermal images and core temperature data were taken by a thermal camera and an ingestible telemetric temperature sensor, respectively.

\subsection{Procedures}

\subsubsection{Anthropometrics and physiological analyses}

$\dot{V} \mathrm{O}_{2}$ and $\mathrm{CO}_{2}$ production $\left(\dot{V} \mathrm{CO}_{2}\right)$ were measured breath by breath by a Quark $b^{2}$ gas analyser (COSMED, Rome, Italy). Heart rate (HR) was measured continuously by an integrated part of the gas analyser and an external hearth rate monitor (Polar RS400; Polar Electro Oy, Kempele, Finland). Device calibrations were undertaken according to the manufacturer's instructions. The determination of body surface areas calculated by DuBois formula [19] and body fat percentage was calculated by using Jackson and Pollock 7-site equation [20]. Metabolic rate and DuBois body surface area were calculated by using (E.1) and (E.2), respectively [21]. Mechanical work values were subtracted from determined metabolic heat production values given in E.1. All procedures were performed using standard condition of $21.3 \pm 0.4{ }^{\circ} \mathrm{C}$ temperature and $64.5 \pm 2.5 \%$ relative humidity in a climatic chamber equipped with the ability to control the temperature and relative humidity, as well as having an integrated heat recovery system by fresh air supplement.

\subsubsection{Thermal data analyses}

$T_{\text {skin }}$ measurements were carried out by infrared thermal camera (Testo 875-1 ThermaCAM, Germany). Participants rested in a seated position in the climatic chamber for a period of 15-min for stabilizing thermal balance before each tests [22]. Clothing was standardized at $\sim 0.1$ Clo (clothing insulation for shorts, socks and sports shoes; $1 \mathrm{Clo}=0.155 \mathrm{~K} \mathrm{~m}^{2} / \mathrm{W}$ ) in order to obtain the thermographic imaging from larger body surface. Since there is limited information about the norms of $T_{\text {skin }}$ measurements in literature, a pilot study was organized to find out $T_{\text {skin }}$ variances of body parts during vary exercise intensities. During pilot studies, monitored thermal image were analysed using an area consisted of at least two reference points. Each area was evaluated with $160 \times 120$ pixel resolution and $<80 \mathrm{mK}\left(0.08^{\circ} \mathrm{C}\right)$ thermal sensitivity. Emissivity value was set at 0.98 [23]. Thermal images were analysed by using the same software of the thermal camera system. Thermal camera was relocated in every two minutes from $1.5 \mathrm{~m}$ front and then $1.5 \mathrm{~m}$ back of participants in both GXT and SE with $90^{\circ}$ angles to obtain thermal image. Lines were drawn on front and back of upper arms and head by using two reference markers. In the sequel, average temperatures on the lines were received. On the other hand, since they have larger skin surfaces, oval and ellipse areas were drawn by using four references points on chest and back, respectively. For the chest, the first reference was placed on second costae of anterior medialis, second reference was placed on fourth costae of arteculatios sternocostalis, third reference was placed on sixth costae of anterior medialis, and fourth reference was placed on a contralateral point to form an oval area. For the back, the first reference was placed on T2 processus spinalis, second reference was placed on T6 processus spinalis, third and fourth references were placed on a horizontal line between right and left scapula on $\mathrm{T} 4 \mathrm{~s}^{\prime}$ when the participant's arm to 90 degrees forward flexion. In the sequel and then average temperature on 
oval and ellipse areas were received (Fig. 1). Results of the pilot study showed that upper arm and head temperatures' homogeneity of variances were not normally distributed, and due to limitation of software program, the arm and head skin temperatures had to be calculated by averaging the temperatures on a line. Thus, $T_{\text {skin }}$ was limited by chest $\left(T_{\text {chest }}\right)$ and back $\left(T_{\text {back }}\right)$ mean temperatures (E.3).

Then a regression was fitted with sixth-degree polynomial equation by using mean $T_{\text {skin }}$ values in SE and GXT for each participant. Multiple non-linear and linear regression analyses were used to test whether the following models sufficiently described the behaviour of the $T_{\text {skin }}$ over time as; (E.4)-(E.8) for SE and GXT respectively. The best regression equation was adopted considering to Rsqr and Sum of square values. Then values were used to estimate breaking point of $T_{\text {skin }}$, and analyse relation of $T_{\text {skin }}$ pattern amongst participants.

Thermal camera had been calibrated in manufacturer's laboratory in the last 6 months. Also female athletes did not take part in the study due to different tissue type in chest region. On the other hand $T_{\text {core }}$ was carried out with ingestible telemetric temperature sensor which transmits data continuously to data logger (VitalSense; Philips Respironics, the Netherlands). The volunteers took temperature pills one hour before their experiments.

\subsubsection{Familiarization sessions}

Familiarization sessions were consisted of two successive sessions. The main purpose of the first familiarization session was to perform anthropometric measurements and adapted participants to cycle ergometer, climatic chamber conditions, face mask of gas analyser and our research group. In the second familiarization session, participants performed a graded exercise which consisting four stages for each 5-min with $\sim 50-60$ Watts initial loading and 27-36 Watts increments. $\mathrm{HR}, \dot{\mathrm{V}} \mathrm{O}_{2}$ and $\dot{\mathrm{V}} \mathrm{CO}_{2}$ were recorded during the test.

\subsubsection{Graded submaximal exercise tests}

Graded submaximal exercise tests were consisted at least four 5 -min stages and the procedure continued until the ventilatory threshold was reached. The test initially started with $50-60 \%$ of $\mathrm{HR}_{\max }$ reserve predicted by Karvonen's HR reserve formula, and each stage workload increased by $\sim 27-36 \mathrm{~W}$. The data used to estimate initial workload of GXT which supposed to be terminated around 8-12 $\min (7)$. $\mathrm{HR}, \dot{V} \mathrm{O}_{2}$ and $\dot{V} \mathrm{CO}_{2}$ were recorded during the test.

\subsubsection{Exercise tests}

GXTs were performed after 30-45 min of submaximal graded exercise test to determine participants' $\dot{V} \mathrm{O}_{2 \max }$. Initial load was adjusted to a workload representing $\sim 70-85 \% \mathrm{HR}_{\max }$ predicted by Karvonen's HR reserve formula. Fixed cadence was $90 \mathrm{rpm}$ through test. Stage durations were set at one 4-min and three 2-min phases, followed by 1-min phases via 27-36 W load increases at each stage. GXT was only terminated athletes' volitional exhaustion. $\dot{V} \mathrm{O}_{2 \max }$ termination quality were examined as follow criteria; (a) a plateau in $\dot{V} \mathrm{O}_{2}$ defined as the $\mathrm{O}_{2}$ requirement difference less than $150 \mathrm{~mL} \mathrm{~min}^{-1}$, (b) HR responses greater than $90 \%$ of age-predicted maximum (220-age) beats/min, (c) respiratory exchange ratio (RER) of 1.10 or above [24]. In addition, rate of perceived exertion (RPE) was also checked by Borg's 15-point scale [25]. $\dot{V} \mathrm{O}_{2 \max }$ was determined as the highest 30 -s average $\dot{V} \mathrm{O}_{2}$ during the test. SE was performed at workload corresponding to $60 \%$ of $\dot{V} O_{2 \max }$ at $90 \mathrm{rpm}$ for $20 \mathrm{~min}$ after a day of GXT. HR, $\dot{V} \mathrm{O}_{2}$, $\dot{V} \mathrm{CO}_{2}, T_{\text {core }}$ and $T_{\text {skin }}$ were recorded throughout the tests.

\subsection{Statistical analysis}

Results were evaluated using SPSS 20.0 (SPSS Inc., Chicago, USA) statistical software. Descriptive results were reported as mean values and standard deviations. Test of normality was evaluated by Shapiro-Wilk [26]. Hypotheses were then tested by means of independent and dependent variables. In order to analyse homogeneity of variance, Levene's test was used [27]. Pearson correlation analysis was used to evaluate relation in mean $T_{\text {skin }}$ and total heat energy values obtained from the same intervals over time throughout GXT and SE. Multiple non-linear regression analyses were used to test whether used models sufficiently described the behaviour of the thermal data over time during GXT and SE (SigmaPlot 12.5, Systat Software, Germany). The best regression equation was selected based on $\geqslant 0.85$ of Rsqr and the lowest sum of square values. Differences between $T_{\text {skin }}$ responses obtained from GXT and SE were analysed by two-factor $2 \times 5$ (Exercise Type $\times$ Time) repeated measures analyses of variance (ANOVA) [28] in order to investigate the interaction effect between factors. To equate thermographic analyse time in GXT and SE, only first 10 min of SE was subjected to statistical analysis. Fisher's Least Significant Difference (LSD) was used as post hoc test to perform pairwise comparisons following a significant $F$-ratio. Confidence interval adjustment was not performed for multiple pairwise comparisons to avoid loss of statistical power $[29,30]$. Results with a $p<0.05$

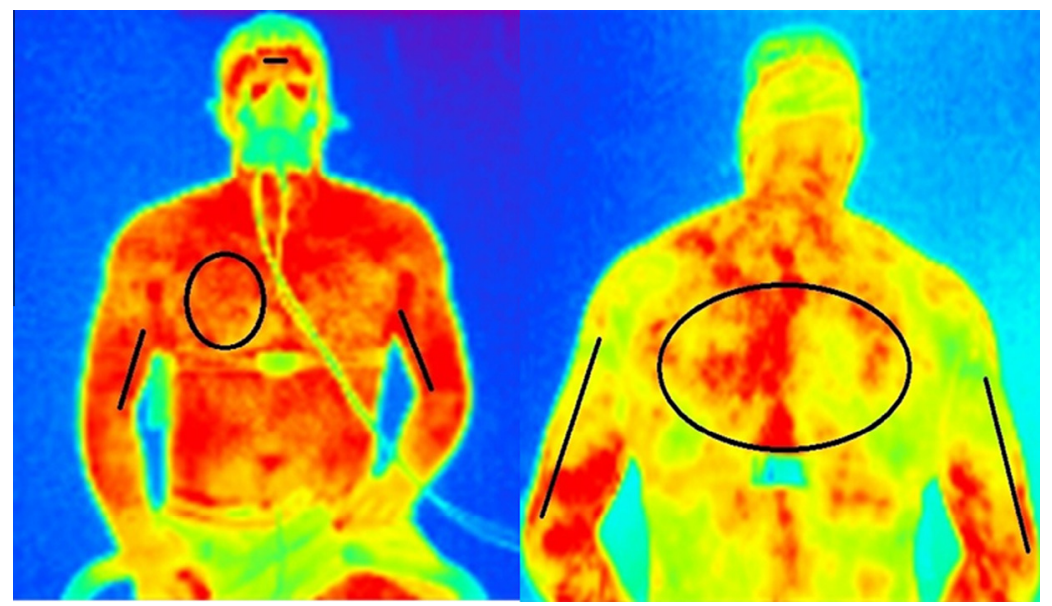

Fig. 1. Skin temperature determination by using thermal imaging. 
were considered statistically significant for all the statistical analyses.

\section{Results}

Thermal kinetic analyses showed that a structural model exists in mean $T_{\text {skin }}$ responses over a time period of each single SE (Rsqr = 0.97) and GXT (Rsqr = 0.89). Thermal kinetic patterns were significantly different between SE and GXT $[F(4,40)=2.67$, $\left.p=0.07, \quad \eta_{p}^{2}=0.211\right] . \quad T_{\text {skin }}$ was gradually decrease till the $7.58 \pm 1.03^{\text {th }}$ minutes, and then initiated an increase till the end of SE, while $T_{\text {skin }}$ was gradually decrease throughout the GXT (Fig. 2). Mean chest skin temperatures were higher than the back region after $8^{\text {th }}$ min of SE ( $\left.p<0.05\right)$ (Fig. 3).

Mean $T_{\text {core }}$ values of the participants significantly increased throughout GXT and SE $(p<0.05)$ (Fig. 4). Additionally, mean initial and final $T_{\text {core }}$ values did not change between GXT and SE ( $T_{\text {core }} @ \mathrm{SE}_{\text {initial }}: \quad 36.8 \pm 0.4{ }^{\circ} \mathrm{C}$ vs. $\quad T_{\text {core }} @ \mathrm{GXT}_{\text {initial }}$ : $36.8 \pm 0.5^{\circ} \mathrm{C}$; $T_{\text {core }} @ \mathrm{SE}_{\text {final }}: \quad 38.0 \pm 0.3{ }^{\circ} \mathrm{C} \quad$ vs. $\quad T_{\text {core }} @ \mathrm{GXT}_{\text {final }}: \quad 37.8 \pm 0.3^{\circ} \mathrm{C}$ ) $(p>0.05)$. Consequently, it was demonstrated that thermal regulation was greater in SE compared to GXT. Mean total heat energy in SE was 59\% higher than GXT (GXT; $261.5 \mathrm{~kJ} / \mathrm{m}^{2}$, and SE; $416 \mathrm{~kJ} / \mathrm{m}^{2}$ ) $(p<0.01)$. Mean metabolic rates remained unchanged throughout the SE $(p>0.05)$ while high correlations existed amongst metabolic rates of 2-min exercise segments in SE ( $r$ : 0.75-0.99).

\section{Discussion}

This is the first study to investigate $T_{\text {skin }}$ responses during SE and GXT by using visual temperature patterns of chest and back in a homogeneous group. Main results of this study indicated that (a) thermal kinetics variations of $T_{\text {skin }}$ had a structural relation in SE and GXT amongst participants, (b) there was a significant difference between $T_{\text {skin }}$ patterns of SE and GXT.

Thermoregulation is an important factor that affects exercise performance [31]. For example, a person without a thermoregulation mechanism, his/her $T_{\text {core }}$ would increase approximately $3^{\circ} \mathrm{C}$ in 20th min while exercising in cycle ergometer even with a low $(150 \mathrm{~W})$ workload at $20 \%$ mechanical efficiency level. For this reason, the thermal behaviour of human body in exercise has become a popular topic in recent years. It is known that $T_{\text {core }}$ is the primary factor that limit exercise, without an increased lactate accumulation and reduction in blood flow [32]. One of the most important way to exchange the heat occurred during the exercise is to transmit the blood flow to the skin layer. The increases in blood flow to the skin add new areas for heat transfer and by this way, $T_{\text {core }}$ is

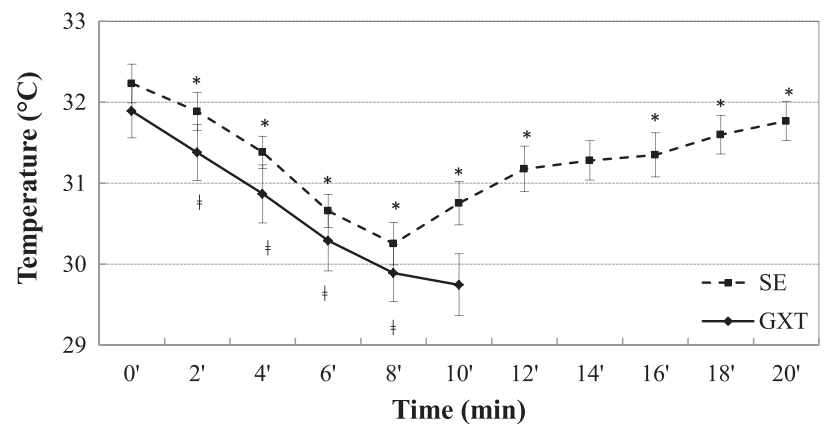

SE: Submaximal Exercise; GXT: Graded Maximal Exercise Test

*: Significant difference in skin temperature between 2-min exercise stages of SE; $p<0.05$

$\ddagger$ : Significant difference in skin temperature between 2-min exercise stages of GXT; $p<0.05$

Fig. 2. Mean skin temperature changes of participants at submaximal exercise and graded maximal exercise test.

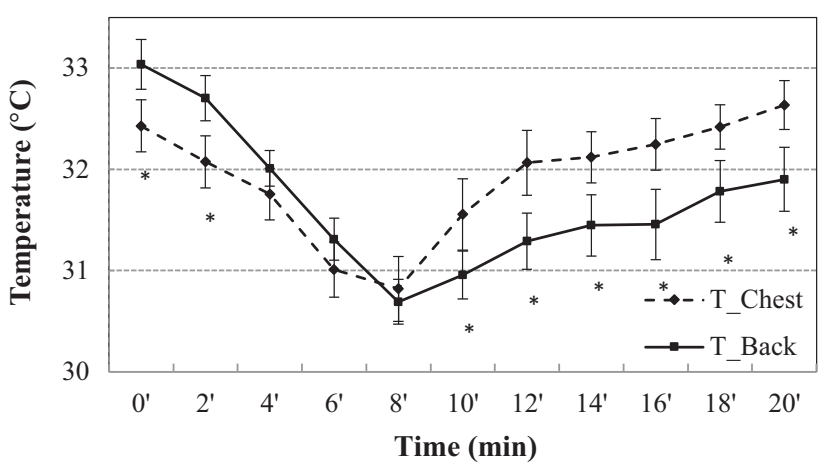

T_Chest: Temperature of chest surface

T Back: Temperature of back surface

* : Significant difference in skin temperature between T_Chest and T_Back; $p<0.05$

Fig. 3. Chest and back mean skin temperature pattern of participants during submaximal exercise.

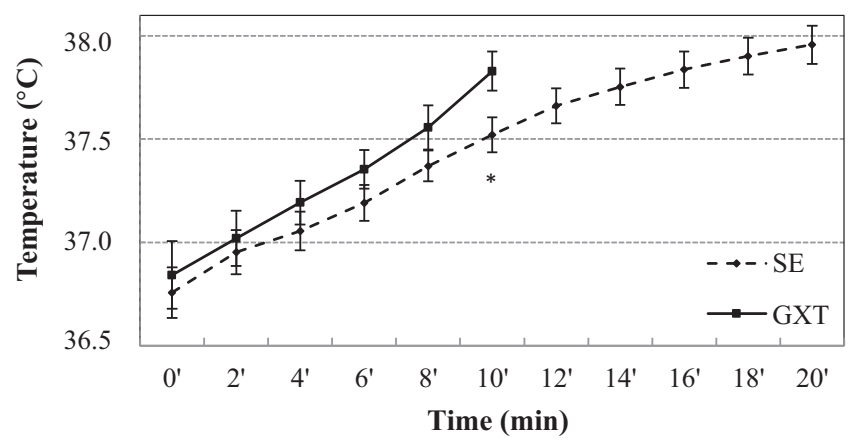

SE: Submaximal Exercise; GXT: Graded Maximal Exercise Test

* : Significant difference in core temperature between SE and GXT; $p<0.05$

Fig. 4. Mean core temperature changes of participants in submaximal exercise and graded maximal exercise test.

stabilized and ensures a better thermoregulation for human body $[33,34]$.

In this study $T_{\text {skin }}$ decreased in both GXTs and SE until the $8^{\text {th }}$ min. Zontak et al. showed a similar relationship on a bicycle ergometer which $T_{\text {skin }}$ decreases during $7^{\text {th }}$ min then increasing after this point in submaximal exercises. In addition $T_{\text {skin }}$ tend to decrease throughout in graded exercise (12 min) [13]. Also Merla et al. indicated a continuous decrement in $T_{\text {skin }}$ in trained runners during a graded-load exercise on a treadmill (12-min) [14]. Torii et al. showed same decreases of $T_{\text {skin }}$ during $7^{\text {th }}$ min in bicycle exercise with submaximal load $(150 \mathrm{~W})$ [10]. Similar decrease was shown during $10 \mathrm{~min}$ localized exercise [12]. In dynamic exercise, skin blood flow is restricted due to increased cutaneous sympathetic vasoconstrictor outflow. This decrease continues until $T_{\text {core }}$ reaches at a threshold which is $\sim 37.2^{\circ} \mathrm{C}$. At this point, the vasodilatation system becomes predominant thus skin blood flow rapidly increases in order to eliminate excessive heat [35-37]. It is suggested that decrease in $T_{\text {skin }}$ at submaximal and maximal exercise are caused by the redistribution of blood flow to the working muscles while increase in $T_{\text {skin }}$ after $\sim 8^{\text {th }}$ min of exercise is related to thermal factor $[10,34]$. Therefore, changes in $T_{\text {skin }}$ after $\sim 8^{\text {th }}$ min in submaximal exercise are interpreted as a thermoregulatory threshold stem from thermal regulatory processes [38]. It was observed that, mean $T_{\text {skin }}$ decreased more dramatically and did not increase after $8^{\text {th }}$ minutes in GXT. This decrease may be related to more blood demand of skeletal muscles in maximal exercise. 
Also thermoregulatory threshold point may be related with exercise performance level in different exercise intensities. For this reason, thermal kinetic analysing could be important method to evaluate performance improvement.

Our study showed that there were no significant differences in final $T_{\text {core }}$ levels between GXT and SE, in spite of total heat energy being $59 \%$ greater in SE. It was demonstrated that thermoregulation was better in SE. This may be related with the shift of the skin blood flow towards active skeletal muscles, serving to sustain their oxygen and substrate delivery based on increased catecholamine and vasoconstrictor hormones [33,34]. Additionally, active muscle has higher surface temperature because of greater skin blood flow [39]. In this study, it was observed that chest surface temperatures were higher than back surface after $8^{\text {th }}$ min of SE. This could be also related with higher muscle activity in chest muscles, and back muscles have larger areas for heat transfer due to exercise position on cycle ergometer.

$T_{\text {skin }}$ is generally measured by contact thermistors [7]. But these covered contact skin thermistors inhibit heat loss from skin [8]. In addition, that thermistors may evaluate only a small part of the skin. If we consider that human body surface approximately $1.80 \mathrm{~m}^{2}$, this is a huge disadvantage to analyse $T_{\text {skin }}$ from spot size. However, infrared thermography provides advantages for $T_{\text {skin }}$ evaluations as collecting data from optional analysing areas in a whole thermal picture without contact to the skin. This may supply more accurate $T_{\text {skin }}$ data because it does not restrict heat loss from skin. Also thermal imaging may be appropriate for non-contact measurements from a distance [9]. In contrast to infrared thermography, there were confusing $T_{\text {skin }}$ results which had been evaluated by contact thermistors in literature as; gradually increase, steady state after an increase and steady state during whole exercise session [40-42]. On the other hand, in recent years, infrared thermography method has become very popular after the development of related technology and correspondingly, reduction of equipment costs [43]. Nowadays, the visual temperature patterns of $T_{\text {skin }}$ which is also a non-invasive and valid method in sport sciences have been widely used [9]. Clark et al. had made the first skin temperature analysis during dynamic exercise using thermal camera in climatic chamber [17] This study had only two participants and $T_{\text {skin }}$ was calculated by averaging the total body segments' temperatures. Some of the studies used multiple spot method with different parts of body $[10,11]$ or single spot method (one pixel) on hand in order to analyse $T_{\text {skin }}$ with dynamic infrared thermography in submaximal and graded exercises [13]. Some other studies calculated $T_{\text {skin }}$ with average geometric areas, in submaximal exercise without markers [12] or in graded exercise with markers on different body parts [14]. Formenti et al. calculated $T_{\text {skin }}$ by using computer-assisted software analysing method in standing heels raise exercise [15]. This software selected five hottest pixels and $T_{\text {skin }}$ was determined averaging around hottest pixels area. Ludwig et al. used average geometric areas and Formentis' analysis method over trunk during breathing exercise in one subject [16]. Quesada et al., calculated $T_{\text {skin }}$ with average of 4 body regions of interest before and after incremental workload cycling test. They use average reference lines for drawing geometric areas in anterior and posterior thigh [44]. All the aforementioned paper used participant/participants with non-homogeneity of BSAs and none of them used back and chest surface for determining $T_{\text {skin }}$.

Additionally, while some of abovementioned studies have been performed in an isolated climatic chamber [10,11,14,17], some studies have not used an isolated climatic chamber $[12,13,15,16,44]$ that could cause some methodological errors since the solar radiation affects.

In this study, geometric analysis method was used over chest and back muscle for determining $T_{\text {skin }}$ in a climatic chamber. Larger muscle surface could be better for $T_{\text {skin }}$ measurements due to less sub-cutaneous fat. Ludwig et al. [16] analysed different parts of anterior trunk and they found high correlation index between left and right major pectoral muscles. Their result also supports our method of determining $T_{\text {skin }}$ from over the chest and back. In addition, our pilot study showed a similar result that upper arms and head temperatures' homogeneity of variances were not normally distributed.

\section{Conclusion}

Skin temperature of anterior and posterior of the upper human body was measured via thermal camera during graded maximal exercise test and submaximal exercise with participants whose body surface areas are similar. The novel result of this study revealed a relation in thermal kinetics of $T_{\text {skin }}$ amongst participants in SE and GXT. Mean $T_{\text {skin }}$ obtained from GXT and SE indicated different patterns. Thermal kinetic analysing may be useful tool for thermoregulatory monitoring purposes in exercise without measuring core temperature.

\section{Conflict of interest}

The authors do not have any conflict of interest.

\section{Acknowledgments}

This study was financially supported by Ege University, Scientific Research Projects Fund [Grant number EGE.BAP-10. BESYO.003]. We would like to thank Ozgur Ozkaya PhD and Ekim Pekunlu PhD for the technical assistance.

\section{Appendix A}

$M\left(\mathrm{~W} / \mathrm{m}^{2}\right)=\frac{\left[21 \cdot(0.23 \cdot R E R+0.77) \cdot Q_{02}\right]}{A_{D}}$

$A_{D}\left(\mathrm{~m}^{2}\right)=0.202 \cdot(\text { mass })^{0.425} \cdot(\text { heigh })^{0.725}$

$M$ : Metabolic rate; RER: Respiratory exchange ratio (-); $Q_{02}$ : Oxygen consumption rate $(\mathrm{ml} / \mathrm{s}) ; A_{D}$ : DuBois body surface area.

$T_{\text {skin }}=\left(T_{\text {chest }}+T_{\text {back }}\right) / 2$

$f(x)=y 0+(-a \cdot x)+\exp (b \cdot x)$

$f(x)=y 0+a \cdot \exp (-b \cdot x)+c \cdot x$

$f(x)=y 0+a \cdot \exp (-b \cdot x)+\exp (c \cdot x)$

$f(x)=y 0-a \cdot x$

$f(x)=y 0+a \cdot \exp (-b \cdot x)$

\section{References}

[1] Y.A. Cengel, M.A. Boles, M. Kanoglu, Thermodynamics: an Engineering Approach, McGraw-Hill, New York, 1998.

[2] B.W. Olesen, G.S. Brager, A better way to predict comfort: The new ASHRAE standard 55-2004, Cent. Built Environ., 2004.

[3] M.N. Sawka, C.B. Wenger, Physiological responses to acute exercise-heat stress, DTIC Document (1988)

[4] C.G. Williams, G.A.G. Bredell, C.H. Wyndham, N.B. Strydom, J.F. Morrison, J. Peter, et al., Circulatory and metabolic reactions to work in heat, J. Appl. Physiol. 17 (1962) 625-638. 
[5] Z.J. Schlader, S.R. Stannard, T. Mündel, Human thermoregulatory behavior during rest and exercise - a prospective review, Physiol. Behav. 99 (2010) 269275, http://dx.doi.org/10.1016/j.physbeh.2009.12.003.

[6] J. González-Alonso, J.A.L. Calbet, Reductions in systemic and skeletal muscle blood flow and oxygen delivery limit maximal aerobic capacity in humans, Circulation 107 (2003) 824-830.

[7] N. Ludwig, D. Formenti, M. Gargano, G. Alberti, Skin temperature evaluation by infrared thermography: comparison of image analysis methods, Infrared Phys. Technol. 62 (2014) 1-6, http://dx.doi.org/10.1016/j.infrared.2013.09.011.

[8] M.J. Buono, R.L. Ulrich, Comparison of mean skin temperature using "covered" versus "uncovered" contact thermistors, Physiol. Meas. 19 (1998) 297-300, http://dx.doi.org/10.1088/0967-3334/19/2/016.

[9] R.P. Clark, M.R. Goff, J.E. Culley, High Resolution Thermography In Medicine, in: Appl. Infrared Technol., International Society for Optics and Photonics, 1988, pp. 36-39.

[10] M. Torii, M. Yamasaki, T. Sasaki, H. Nakayama, Fall in skin temperature of exercising man, Br. J. Sports Med. 26 (1992) 29-32, http://dx.doi.org/10.1136/ bjsm.26.1.29.

[11] T. Nakayama, Y. Ohnuki, K. Kanosue, Fall in skin temperature during exercise observed by thermography, Jpn. J. Physiol. 31 (1981) 757-762, http://dx.doi. org/10.2170/jjphysiol.31.757.

[12] J.J.a. Ferreira, L.C.S. Mendonça, L.a.O. Nunes, a.C.C. Andrade Filho, J.R. Rebelatto, T.F. Salvini, Exercise-associated thermographic changes in young and elderly subjects, Ann. Biomed. Eng. 36 (2008) 1420-1427, http://dx.doi.org/10.1007/ s10439-008-9512-1.

[13] a. Zontak, S. Sideman, O. Verbitsky, R. Beyar, Dynamic thermography: analysis of hand temperature during exercise, Ann. Biomed. Eng. 26 (1998) 988-993, http://dx.doi.org/10.1114/1.33.

[14] A. Merla, P.a. Mattei, L. Di Donato, G.L. Romani, Thermal imaging of cutaneous temperature modifications in runners during graded exercise, Ann. Biomed. Eng. 38 (2010) 158-163, http://dx.doi.org/10.1007/s10439-009-9809-8.

[15] D. Formenti, N. Ludwig, M. Gargano, M. Gondola, N. Dellerma, A. Caumo, et al., Thermal imaging of exercise-associated skin temperature changes in trained and untrained female subjects, Ann. Biomed. Eng. 41 (2013) 863-871, http:// dx.doi.org/10.1007/s10439-012-0718-x.

[16] N. Ludwig, M. Gargano, D. Formenti, D. Bruno, L. Ongaro, G. Alberti, Breathing training characterization by thermal imaging: a case study, Acta Bioeng. Biomech./Wrocław Univ. Technol. 14 (2012) 41-47, http://dx.doi.org/10.5277/ abb120306.

[17] B.Y.R.P. Clark, B.J. Mullan, L.G.C.E. Pught, W. Road, M. Hal, R. April, INFRA-RED COLOUR THERMOGRAPHY Division of Hospital Infection Clinical Research Centre, 1977, pp. 53-62.

[18] O. Jay, A.R. Bain, T.M. Deren, M. Sacheli, M.N. Cramer, Large differences in peak oxygen uptake do not independently alter changes in core temperature and sweating during exercise, Am. J. Physiol. Regul. Integr. Comp. Physiol. 301 (2011) R832-R841, http://dx.doi.org/10.1152/ajpregu.00257.2011.

[19] D. Du Bois, E.F. Du Bois, A formula to estimate the approximate surface area if height and weight be known. 1916, Nutrition 5 (1989) 303.

[20] A.S. Jackson, M.L. Pollock, Generalized equations for predicting body density of men, Br. J. Nutr. 40 (1978) 497-504.

[21] Y. Nishi, Measurement of thermal balance of man, Stud. Environ. Sci. 10 (1981) 29-39.

[22] J.C.B. Marins, D.G. Moreira, S.P. Cano, M.S. Quintana, D.D. Soares, A.D.A. Fernandes, et al., Time required to stabilize thermographic images at rest, Infrared Phys. Technol. 65 (2014) 30-35, http://dx.doi.org/10.1016/j. infrared.2014.02.008.
[23] C. Villaseñor-Mora, F.J. Sanchez-Marin, S. Calixto-Carrera, An indirect skin emissivity measurement in the infrared thermal range through reflection of a CO2 laser beam, Rev. Mex. Fis. 55 (2009) 387-392.

[24] A.W. Midgley, S. Carroll, Emergence of the verification phase procedure for confirming "true"VO2max, Scand. J. Med. Sci. Sports. 19 (2009) 313-322.

[25] A.W. Midgley, L.R. McNaughton, R. Polman, D. Marchant, Criteria for determination of maximal oxygen uptake, Sport. Med. 37 (2007) 1019-1028.

[26] S.S. Shapiro, M.B. Wilk, H.J. Chen, A comparative study of various tests for normality, J. Am. Stat. Assoc. 63 (1968) 1343-1372.

[27] H. Levene, Robust tests for equality of variances1, Contrib. Probab. Stat. Essays Honor Harold Hotell. 2 (1960) 278-292.

[28] W.G. Hopkins, Measures of reliability in sports medicine and science, Sport. Med. 30 (2000) 1-15.

[29] S. Nakagawa, A farewell to Bonferroni: the problems of low statistical power and publication bias, Behav. Ecol. 15 (2004) 1044-1045.

[30] T.V. Perneger, What's wrong with Bonferroni adjustments, BMJ Br. Med. J. 316 (1998) 1236.

[31] S. Robinson, Temperature regulation in exercise, Pediatrics 32 (1963) 691-702.

[32] B. Nielsen, J.R. Hales, S. Strange, N.J. Christensen, J. Warberg, B. Saltin, Human circulatory and thermoregulatory adaptations with heat acclimation and exercise in a hot, dry environment, J. Physiol. 460 (1993) 467-485.

[33] W.L. Kenney, J.M. Johnson, Control of skin blood flow during exercise, Med. Sci. Sports Exerc. 24 (1992) 303-312.

[34] J.M. Johnson, 3: exercise and the cutaneous circulation, Exerc. Sport Sci. Rev. 20 (1992) 59-98.

[35] G.H. Simmons, B.J. Wong, L.A. Holowatz, W.L. Kenney, Changes in the control of skin blood flow with exercise training: where do cutaneous vascular adaptations fit in?, Exp Physiol. 96 (2011) 822-828.

[36] W.L. Kenney, C.G. Tankersley, D.L. Newswanger, S.M. Puhl, Alpha 1-adrenergic blockade does not alter control of skin blood flow during exercise, Am. J. Physiol. Circ. Physiol. 260 (1991) H855-H861.

[37] J. Stapleton, D. Gagnon, G.P. Kenny, Short-term exercise training does not improve whole-body heat loss when rate of metabolic heat production is considered, Eur. J. Appl. Physiol. 109 (2010) 437-446, http://dx.doi.org/ 10.1007/s00421-010-1380-3.

[38] G.P. Kenny, C.E. Proulx, P.M. Denis, G.G. Giesbrecht, Moderate exercise increases the post exercise resting warm thermoregulatory response thresholds, Aviat. Space. Environ. Med. 71 (2000) 914-919.

[39] N.A.S. Taylor, M.J. Tipton, G.P. Kenny, Considerations for the measurement of core, skin and mean body temperatures, J. Therm. Biol. 46 (2014) 72-101.

[40] R. Tucker, L. Rauch, Y.X.R. Harley, T.D. Noakes, Impaired exercise performance in the heat is associated with an anticipatory reduction in skeletal muscle recruitment, Pflügers Arch. 448 (2004) 422-430.

[41] J. González-Alonso, C. Teller, S.L. Andersen, F.B. Jensen, T. Hyldig, B. Nielsen, Influence of body temperature on the development of fatigue during prolonged exercise in the heat, J. Appl. Physiol. 86 (1999) 1032-1039.

[42] A.J. Tatterson, A.G. Hahn, D.T. Martini, M.A. Febbraio, Effects of heat stress on physiological responses and exercise performance in elite cyclists, J. Sci. Med. Sport. 3 (2000) 186-193.

[43] A. Rogalski, Infrared detectors: an overview, Infrared Phys. Technol. 43 (2002) 187-210, http://dx.doi.org/10.1016/S1350-4495(02)00140-8.

[44] J.I. Priego Quesada, F.P. Carpes, R.R. Bini, R. Salvador Palmer, P. Pérez-Soriano, R.M. Cibrián Ortiz de Anda, Relationship between skin temperature and muscle activation during incremental cycle exercise, J. Therm. Biol. 48 (2015) 28-35, http://dx.doi.org/10.1016/j.jtherbio.2014.12.005. 